\title{
THE DEFINITION AND MACROEVOLUTIONARY STUDY OF PLANKTIC FORAMINIFERAL HIGHER TAXA
}

D'HONDT, Steven, Graduate School of Oceanography, University of Rhode Island, Narragansett, RI, 02882, U.S.A.

Planktic foraminiferal species are generally assigned to higher taxa on the basis of shared morphologic characters and stratigraphic age. These assignments are usually justified on the basis of apparent phyletic relationships. Extant species assigned to the same genera usually exhibit similar trophic and reproductive behavior and are associated with similar watermasses. Paleogeographic and stable isotopic data suggest that coeval fossil species also generally exhibit similar paleoecologic and paleoceanographic associations within well-constrained genera.

Despite shared morphologic characters and stratigraphic and paleoenvironmental associations, many higher taxa of planktic foraminifera are not believed to be monophyletic. Many superspecific taxa are widely accepted as paraphyletic (i.e. Guembelitria, Heterohelix). Such paraphyly has commonly resulted from maintaining a different generic or familial name for descendant species that diverge strongly from their ancestral bauplan. Additionally, some higher taxa appear to be polyphyletic (i.e. Eoglobigerinidae, Globorotalia).

As presently defined, superspecific taxa--commonly paraphyletic--can generally be used to examine relative radiation and extinction rates within and between different planktic foraminiferal adaptive zones. For example, analysis of Paleocene genera demonstrates rapid earliest Paleocene origination and radiation of sea-surface-dwelling and deeper-dwelling biserial and trochospiral genera. This earliest Paleocene radiation is quickly followed by disappearance of these surface-dwelling genera and some deeper-dwelling genera, in turn followed by major radiation within new surfacedwelling trochospiral genera in the mid and Late Paleocene. Such analysis documents the relative diversity and succession of major adaptive groups, regardless of their phylogenetic relationships.

The phyletic status of existing superspecific taxa does not preclude macroevolutionary study of monophyletic groups--or require that presently paraphyletic taxa be subsurned into larger monophyletic taxa. It simply requires that study of monophyletic groups be explicitly based on cladograms or phylogenetic trees. Such studies can address topics of clear macroevolutionary interest, including (i) the relative diversity and longevity of different monophyletic groups and (ii) general patterns of origination and extinction within clades. Additionally, while phylogenetic analysis is not necessary to determine patterns of succession and diversity of within and between adaptive groups, it can amplify our understanding of such patterns. For example, the earliest Paleocene appears to be marked by extremely rapid radiation within two monophyletic groups. The first reaches peak diversity within the earliest Paleocene and dominates earliest Paleocene planktic foraminiferal assemblages, but decreases radically in diversity and abundance within the Early Paleocene. The second continues to diversify throughout the Paleocene and dominates mid and Late Paleocene faunas. Consideration of phylogenetic and paleoecologic relationships within and between both monophyletic groups clearly reveals convergent evolution of deep and surface-dwelling morphotypes, and of biserial and trochospiral forms. 